Научная статья

УДК 538.9:539.25:620.186:621.791.13

DOI 10.18101/2306-2363-2021-1-52-65

\title{
ИССЛЕДОВАНИЕ СТРУКТУРЫ, МИКРОТВЕРДОСТИ \\ И РАСПРЕДЕЛЕНИЯ ХИМИЧЕСКИХ ЭЛЕМЕНТОВ \\ В ПОГРАНИЧНОМ СЛОЕ БИМЕТАЛЛИЧЕСКОГО СОЕДИНЕНИЯ \\ ИЗ СТАЛИ И ЛАТУНИ, ПОЛУЧЕННОГО МЕТОДОМ СВАРКИ ВЗРЫВОМ
}

\section{(C) Лупсанов А. Б.}

аспирант

Институт физического материаловедения СО РАН

670047, Россия, Улан-Удэ, ул. Сахьяновой, 6

преподаватель

Бурятский государственный университет имени Доржи Банзарова

670000, Россия, Улан-Удэ, ул. Смолина, 24 «а»

lupandrey@yandex.ru

\section{(C) Милонов А. С.}

кандидат технических наук, старший научный сотрудник

Институт физического материаловедения СО РАН

670047, Россия, Улан-Удэ, ул. Сахьяновой, 6

terwer81@mail.ru

(C) Мишигдоржийн У. Л.

кандидат технических наук, зав. лабораторией

Институт физического материаловедения СО РАН

670047, Россия, Улан-Удэ, ул. Сахьяновой, 6

druh@mail.ru, undrakh@ipms.bscnet.ru

\section{(C) Номоев А. В.}

доктор физико-математических наук, доцент, зав. лабораторией, директор

Институт физического материаловедения СО РАН

670047, Россия, Улан-Удэ, ул. Сахьяновой, 6

доцент кафедры общей и теоретической физики,

Бурятский государственный университет имени Доржи Банзарова

670000, Россия, Улан-Удэ, ул. Смолина, 24 «а»

nomoevav@mail.ru

Аннотация. В работе представлены результаты исследований микроструктуры, микротвердости и распределения химических элементов в пограничном слое сварных соединений, полученных посредством сварки взрывом, между пластинами стали Ст 3 и латуни Л 63 в биметаллическом подшипнике скольжения по типу «втулка». Анализ пограничного (переходного) слоя соединения выявил единичный дефект - «воздушный пузырь», предположительно образованный газовыми продуктами, выделившимися при химической реакции элементов, взрывчатого вещества. Других значимых дефектов в переходном слое соединения обнаружено не было. Граница соединения имеет волнообразную структуру, где показатели длины и амплитуды волны составляют $1,065 \times 10^{3}$ и 173 мкм соответственно. Толщина погра- 
Лупсанов А. Б., Милонов А. С., Мишигдоржийн У. Л., Номоев А. В. Исследование структуры, микротвердости и распределения химических элементов...

ничного (переходного) слоя варьируется в пределах от 1,3 до 43,7 мкм, среднее значение составляет 15,5 мкм. В данном переходном слое наблюдается взаимопроникновение стали и латуни, чем достигается особо прочное соединение, обладающее комбинированными характеристиками микротвердости.

Ключевые слова: Сварка взрывом, биметалл, втулка, пограничный (переходной) слой, микроструктура, микротвердость.

\section{Для цитирования}

Лупсанов А. Б., Милонов А. С., Мишигдоржийн У. Л., Номоев А. В. Исследование структуры, микротвердости и распределения химических элементов в пограничном слое биметаллического соединения из стали и латуни, полученного методом сварки взрывом // Вестник Бурятского государственного университета. Химия. Физика. 2021. Вып. 1. С. 52-65.

\section{Введение}

Для развития машиностроения и промышленности в целом необходимо постоянно улучшать характеристики наиболее нагруженных узлов трения (трибосистем) в машинах и в оборудовании. Такая модернизация должна проходить на основе рационального конструирования, выбора высокоэффективных материалов, упрочняющих технологий и износостойких покрытий, обеспечивающих оптимальные условия трения и высокую сопротивляемость изнашиванию.

В машиностроительном производстве в качестве основных трибосистем часто используются различные подшипники скольжения, обладающие высокими антифрикционными свойствами, коррозионной стойкостью, выдерживающие значительные удельные нагрузки и высокие скоростные режимы. Широкое распространение получили подшипники скольжения типа «втулка», а одним из самых рациональных путей повышения прочности сцепления антифрикционного покрытия и износостойкости таких втулок является применение биметаллических соединений, где внутренняя (трущаяся) сторона выполнена из различных сплавов (чаще всего на основе меди), а внешняя из стали [1].

При использовании таких биметаллических втулок при трении из медного сплава легирующие элементы уходят в смазочный материал, а из меди образуется тонкая неокисляющаяся металлическая пленка толщиной $1,0 \ldots 1,5$ мкм с особыми свойствами - она пориста, имеет малое число дислокаций и большое количество вакансий, обладает низким сопротивлением сдвигу, а параметр её кристаллической решетки отличен от параметра решетки металла, полученного металлургическим путем [2]. Обнаруженную пленку ученые назвали «сервовитной», то есть спасающая или сберегающая жизнь (от лат. servo - сторожить, охранять, сберегать, сохранять, спасать и vita - жизнь [3]), за счет нее износостойкость поверхности поднимается до двух порядков, а силы трения снижаются на порядок по сравнению с аналогичными условиями трения при граничной смазке [4]. Данный эффект был экспериментально установлен в 1956 г. Гаркуновым Д. Н. и Крагельским И. В. и стал известен под названием избирательный перенос (ИП), в технической литературе его часто называют эффектом безызносности [4]. Это явление, по своему характеру противоположно изнашиванию, при котором во время трения все процессы в зоне контакта сводятся к разрушению поверхности, а здесь же процессы носят созидательный характер: они защищают поверхности сопряжения от износа и заедания и относятся к самоорга- 
низующимся процессам неживой природы и подобны процессам в узлах трения живой природы (живого организма) [2].

Получить соединение стали и меди (медных сплавов) в обычных условиях является достаточно непростой задачей, так как медь и железо имеют крайне ограниченную взаимную растворимость в твердом состоянии, обладают весьма посредственной взаимной смачиваемостью, а температуры их кристаллизации значительно расходятся, поэтому одним из основных способов получения прочных соединений таких металлов является сварка взрывом [5].

Райнхарт Дж. С., Пирсон Дж. пишут [6], что «Сварка взрывом - это способ сварки, основанный на использовании энергии взрыва. Привариваемая (метаемая) деталь располагается под углом к неподвижной детали (мишени). При соударении деталей от взрыва образуется кумулятивная струя металла, распространяющаяся по поверхности деталей, вследствие чего происходит совместная пластическая деформация обеих деталей, и они свариваются.» По мнению Дерибаса А.А. [5] «сварка взрывом - это явление прочного соединения двух или нескольких металлических тел, происходящее при их соударениях. Для большей части металлов и сплавов скорость такого соударения должна находится в диапазоне от 0,3 до 1,5 км/с и достигается посредством взрыва взрывчатого вещества (BB).»

Ниже представлена типичная схема сварки взрывом двух заготовок в виде металлических пластин (рис. 1). Пластины из свариваемых металлов расположены одна над другой на некотором расстоянии. На поверхности метаемой пластины равномерным слоем распределено ВВ (рис. 1a). Детонатор устанавливается на краю пластины, после того, как с его помощью инициируется процесс взрыва, то детонационная волна, распространяющаяся с огромной скоростью по заряду ВВ, приводит к образованию газообразных продуктов, под давлением которых метаемая пластина изгибается и на большой скорости косо соударяется с неподвижной пластиной (рис. 1б). При определённых режимах соударения (скорости и угле соударения) происходит формирование прочного соединения [8].
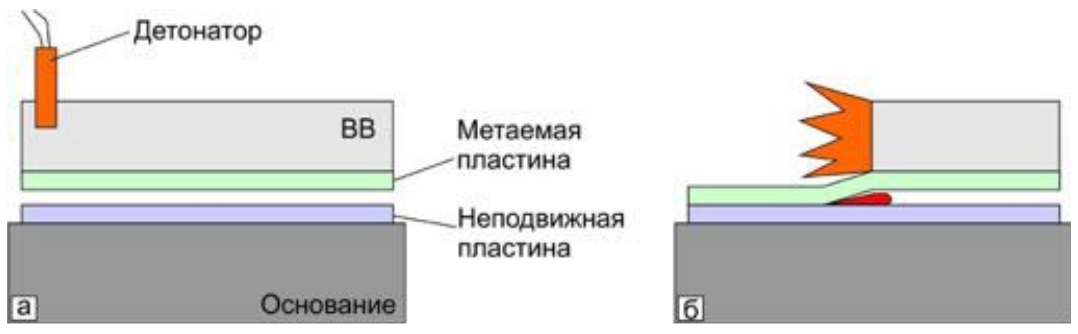

Рис. 1. Типичная схема сварки взрывом

с исходным параллельным расположением металлических пластин [8]

\section{Материалы и методы исследования}

Для изготовления втулки для балансира автомобиля КАМАЗ из биметаллического листа берется лист стали (Ст 3 , толщ. 8 мм $300 \times 1500$ см) и латуни (Л 63, толщ. 2 мм $300 \times 1500$ см) затем оба листа свариваются взрывом, после чего полученный лист рубится на гильотинных ножницах в полосы шириной 32 мм. По- 
Лупсанов А. Б., Милонов А. С., Мишигдоржийн У. Л., Номоев А. В. Исследование структуры, микротвердости и распределения химических элементов...

сле чего полосы свариваются по стали в ленту, которую на специальном станке сворачивают в спиральную трубу с одновременной сваркой по стали полуавтоматом в среде $\mathrm{CO}_{2}$. Далее, труба режется на заготовки.

Исследуемая втулка изготовлена из такой же биметаллической полоски толщиной 10 мм, которая прокатывается на самодельном прокатном станке в полоску толщиной 6 мм, после чего полученная заготовка сворачивается на ручном гидравлическом прессе и стык краев сваривается полуавтоматом в среде $\mathrm{CO}_{2}$.

Снимки микроструктур были сделаны с помощью металлографического микроскопа МЕТАМ РВ-21. Для определения толщины слоя по снимку использовался растровый графический редактор GIMP 2.10.22.

Химический состав структуры вблизи и на границе раздела исследовались с помощью растрового электронного микроскопа JSM-6510LV JEOL (Япония) с системой микроанализа INCA Energy 350, Oxford Instruments (Великобритания) в ЦКП «Прогресс» ФГБОУ ВО «Восточно-Сибирский государственный университет технологий и управления».

Определение показателя микротвердости стали, латуни и переходного слоя выполнялась микротвердомером ПМТ-3М. Расчет микротвердости проводился по методу восстановленного отпечатка (ГОСТ 9450-76) на программном комплексе Nexsys ImageExpert MicroHandness 2. Испытание на микротвердость проводилась вдавливанием по методу восстановленного отпечатка, которое заключается в нанесении на испытуемую поверхность изделия (образца) отпечатка под действием статической нагрузки в 50 г, приложенной к алмазному наконечнику четырехгранной пирамиды с квадратным основанием в течение определенного времени. После удаления нагрузки и измерения параметров полученного отпечатка число микротвердости определяют делением приложенной к алмазному наконечнику нормальной нагрузки на условную площадь боковой поверхности полученного отпечатка.

Формула для определения числа микротвердости [9]:

$$
H V=\frac{F}{S}=\frac{0,102 \times 2 F \sin \frac{D}{2}}{D^{2}}=0,189 \frac{F}{D^{2}}
$$

где, $F$ выражена в ньютонах.

Промеры проводились с шагом в 50 мкм и с отступом от поверхности в 50 мКм.

\section{Результаты исследования и их обсуждение}

На снимке (рис. 2), полученном с помощью РЭМ при увеличении 30 крат четко видна граница раздела между металлами. Граница раздела не является гладкой, а имеет волнообразный характер, что обеспечивает дополнительное сцепление стали и латуни между собой. Показатели длины и амплитуды волны существенно различаются по продольному направлению, средняя величина составляет $1,065 \times 10^{3}$ и 173 мкм соответственно. Волнообразность границы несовершенна, так как присутствуют искажения и отклонения от идеальной периодической формы, однако похожая картина наблюдалась исследователями и при сварке других металлов и является скорее правилом, нежели исключением [10, $11]$. 


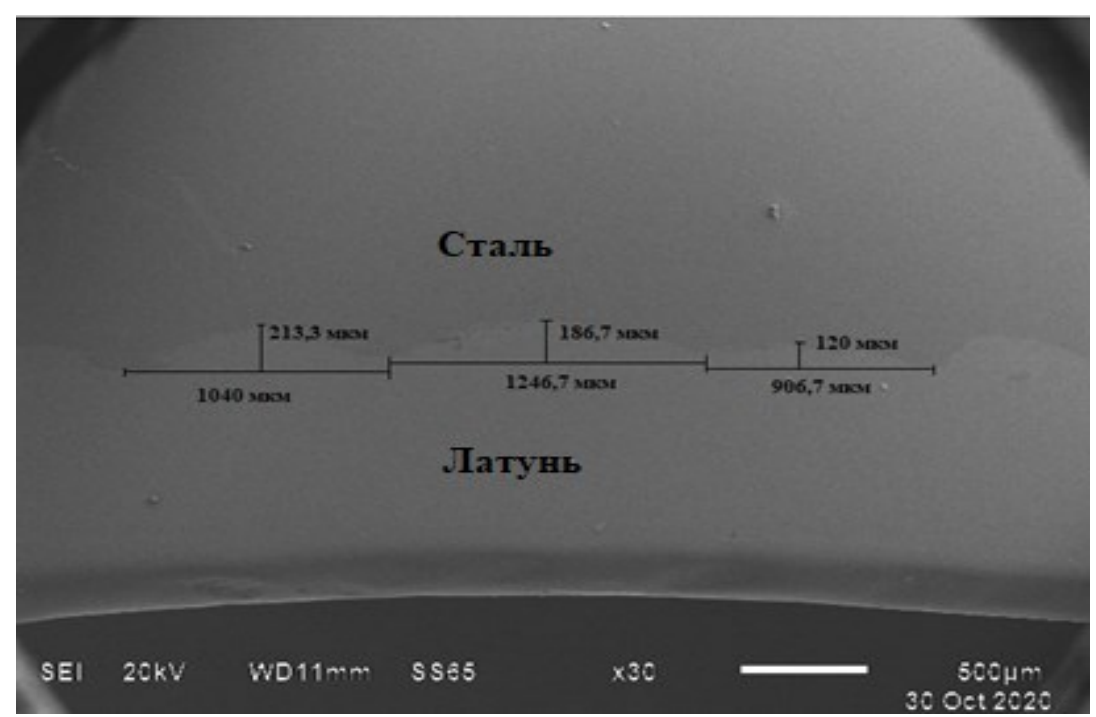

Рис. 2. Граница раздела между сталью и латунью (увеличение х30)

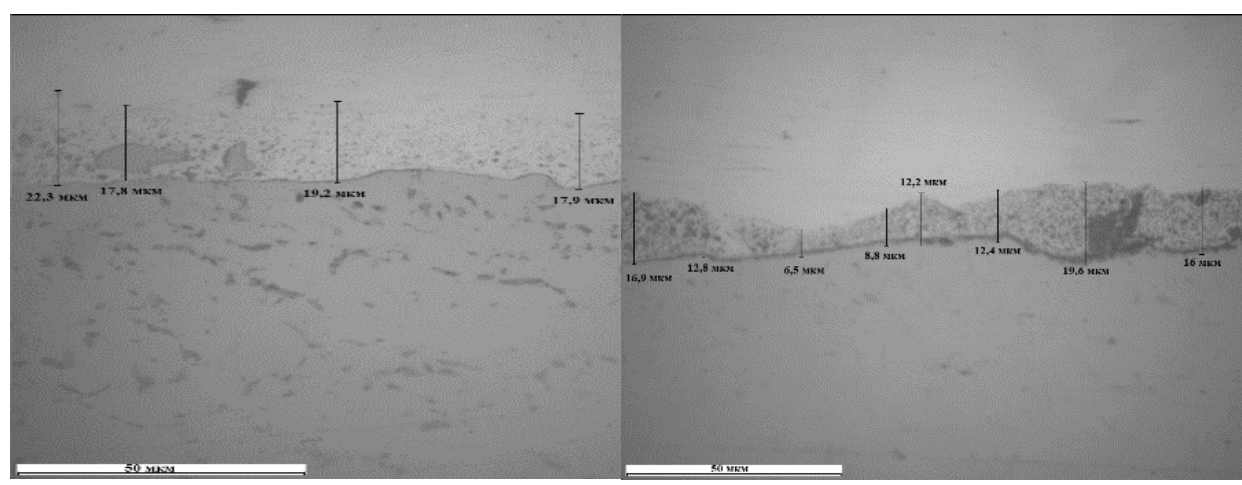

Рис. 3. Пограничный (переходный)

Рис. 4. Пограничный (переходный) слой слой между сталью (сверху) и латумежду сталью (сверху) и латунью (снизу) нью (снизу)

На снимках (рис. 3-6), полученных с помощью металлографического микроскопа, хорошо различима граница раздела с характерным пограничным (переходным) слоем, где можно наблюдать взаимопроникновение частиц латуни и стали между собой латуни за счет чего, предположительно, и достигается прочное сцепление между металлами. Толщина этого слоя неравномерна и варьируется в широких пределах. Так, например, на рис. 3 среднее значение 19,3 мкм, на рис. $4-13,2$ мкм, на рис. $5-5$ мкм, а на рис. $6-35,6$ мкм, в целом же по всем измерениям среднее значение становится равным 15,5 мкм. 
Лупсанов А. Б., Милонов А. С., Мишигдоржийн У. Л., Номоев А. В. Исследование структуры, микротвердости и распределения химических элементов...

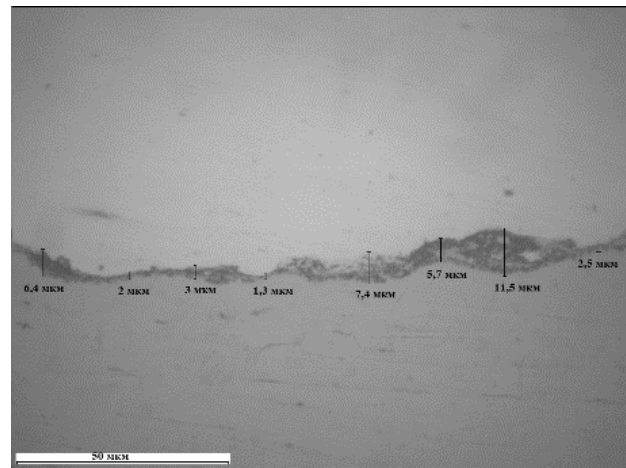

Рис. 5. Пограничный (переходный) слой между сталью (сверху) и латунью (снизу)

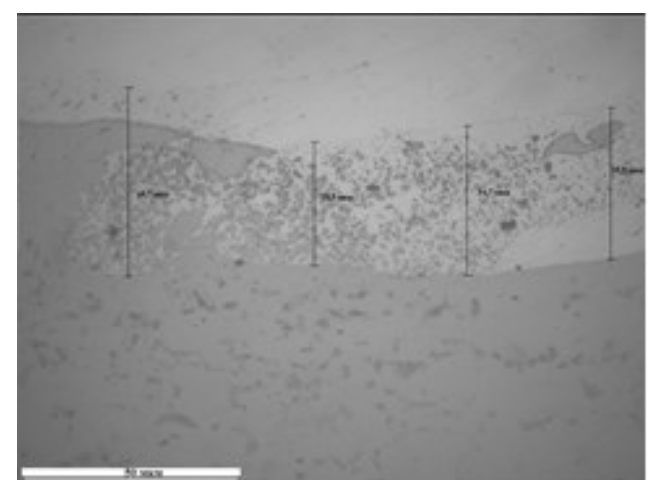

Рис. 6. Пограничный (переходный) слой между сталью (сверху) и латунью (снизу)

На изображениях (рис. 7-12) показаны характерные снимки промеров в стали, в латуни, в районе переходного слоя (в приграничной зоне) и в самом переходном слое.

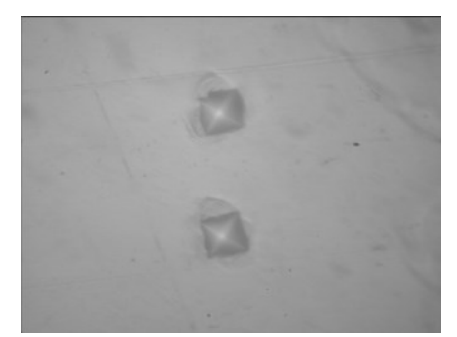

Рис. 7. Промеры в стали (увеличение х450)

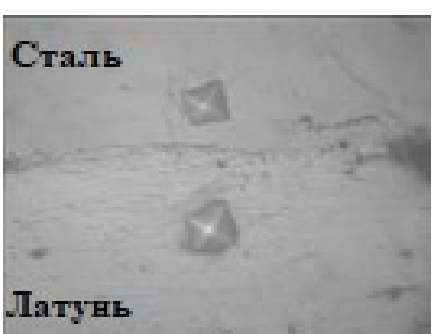

Рис. 8. Промеры в приграничной зоне (увеличение $\mathrm{x} 450$ )

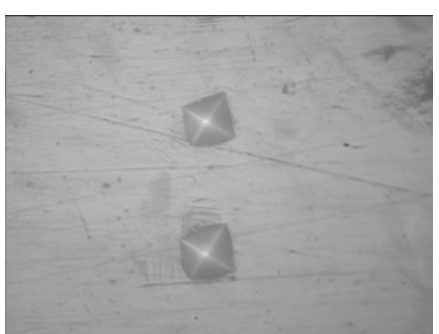

Рис. 9. Промеры в латуни (увеличение х450)

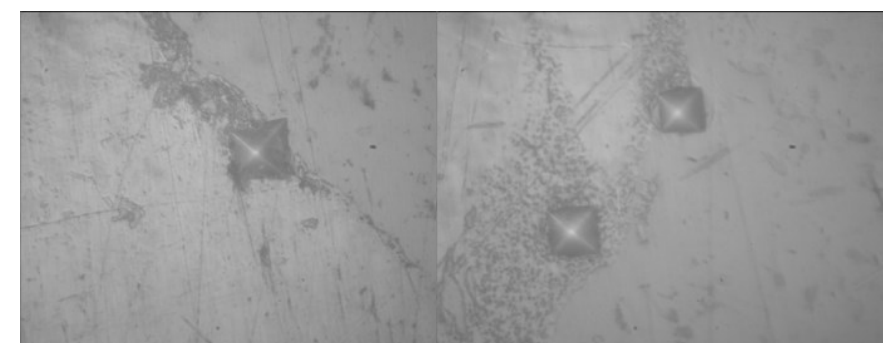

Рис. 10. Промер в переРис. 11. Промеры в переходном слое (увеличение $\mathrm{x} 450)$ ходном слое (увеличение $\mathrm{x} 450$ )

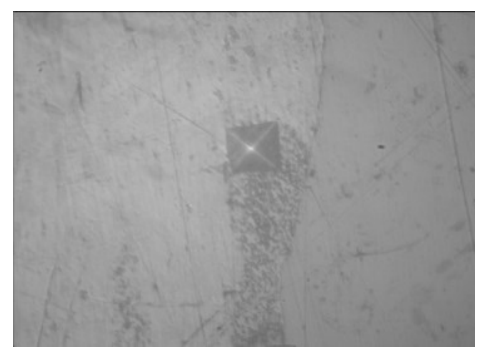

Рис. 12. Промер в переходном слое (увеличение $\mathrm{x} 450$ )

По результатам промеров составлена таблица для стали (табл. 1), для латуни (табл. 2) и для переходного слоя (табл. 3). В табл. 1 мы видим, что среднее значение показателя микротвердости стали, по результатам семи промеров, составило $222 \mathrm{HV}$. 
Расчет показателя микротвердости стали

\begin{tabular}{|c|c|c|c|c|}
\hline № & D сред, мкм & D макс, мкм & D мин, мкм & HV \\
\hline 1 & 20,7 & 21,2 & 20,3 & 215,3 \\
\hline 2 & 20,9 & 21,0 & 20,8 & 212,8 \\
\hline 3 & 21,3 & 21,7 & 20,9 & 204,0 \\
\hline 4 & 20,4 & 20,7 & 20,1 & 222,9 \\
\hline 5 & 19,2 & 19,7 & 18,7 & 250,7 \\
\hline 6 & 20,4 & 20,8 & 20,0 & 223,1 \\
\hline 7 & 20,3 & 20,3 & 20,3 & 224,8 \\
\hline $\begin{array}{c}\text { Среднее значе- } \\
\text { ние }\end{array}$ & $\mathbf{2 0 , 5}$ & $\mathbf{2 0 , 8}$ & $\mathbf{2 0 , 2}$ & $\mathbf{2 2 2}$ \\
\hline
\end{tabular}

В табл. 2 среднее значение показателя микротвердости латуни, по результатам семи промеров, составило $135 \mathrm{HV}$.

Таблица 2

Расчет показателя микротвердости латуни

\begin{tabular}{|c|c|c|c|c|}
\hline № & D сред, мкм & D макс, мкм & D мин, мкм & HV \\
\hline 1 & 24,8 & 24,8 & 24,8 & 150,9 \\
\hline 2 & 26,6 & 27,2 & 26,0 & 130,9 \\
\hline 3 & 25,9 & 26,9 & 24,9 & 138,5 \\
\hline 4 & 24,9 & 26,0 & 23,8 & 149,1 \\
\hline 5 & 27,1 & 28,3 & 26,0 & 125,9 \\
\hline 6 & 27,3 & 27,5 & 27,1 & 124,1 \\
\hline 7 & 26,8 & 27,1 & 26,6 & 128,9 \\
\hline $\begin{array}{c}\text { Среднее значе- } \\
\text { ние }\end{array}$ & $\mathbf{2 6 , 2}$ & $\mathbf{2 6 , 8}$ & $\mathbf{2 5 , 6}$ & $\mathbf{1 3 5}$ \\
\hline
\end{tabular}

В табл. 3 среднее значение показателя микротвердости переходного слоя, по результатам пяти промеров, составило $164 \mathrm{HV}$.

Таблица 3

Расчет показателя микротвердости переходного слоя

\begin{tabular}{|c|c|c|c|c|}
\hline № & D сред, мкм & D макс, мкм & D мин, мкм & HV \\
\hline 1 & 28,3 & 29,4 & 27,2 & 115,6 \\
\hline 2 & 24,6 & 25,4 & 23,8 & 153,6 \\
\hline 3 & 21,4 & 21,7 & 21,0 & 203,4 \\
\hline 4 & 23,8 & 24,0 & 23,7 & 163,4 \\
\hline 5 & 22,4 & 23,0 & 21,8 & 185,1 \\
\hline $\begin{array}{l}\text { Среднее значе- } \\
\text { ние }\end{array}$ & $\mathbf{2 4 , 1}$ & $\mathbf{2 4 , 7}$ & $\mathbf{2 3 , 5}$ & $\mathbf{1 6 4}$ \\
\hline
\end{tabular}

По результатам всех промеров составлен график распределения микротвердости (рис. 13), где масштаб переходного слоя урупнен для наглядности. Оче- 
Лупсанов А. Б., Милонов А. С., Мишигдоржийн У. Л., Номоев А. В. Исследование структуры, микротвердости и распределения химических элементов...

видно, что микротвердость переходного слоя имеет промежуточное значение между показателями микротвердости в стали и в латуни.

Можно предположить, что образование таких пузырей происходит из-за недостаточной очистки поверхности металлов и/или же нарушением механизма самоочищения, описанного Дерибасом А. А. [5], которое можно в свою очередь объяснить образованием областей, где газ был не до конца выдавлен из-за флуктуаций в скорости ударно-сжатого газа, вызванных неоднородностью ВВ и/или недостаточно равномерным его распределением по поверхности метаемой пластины [12].

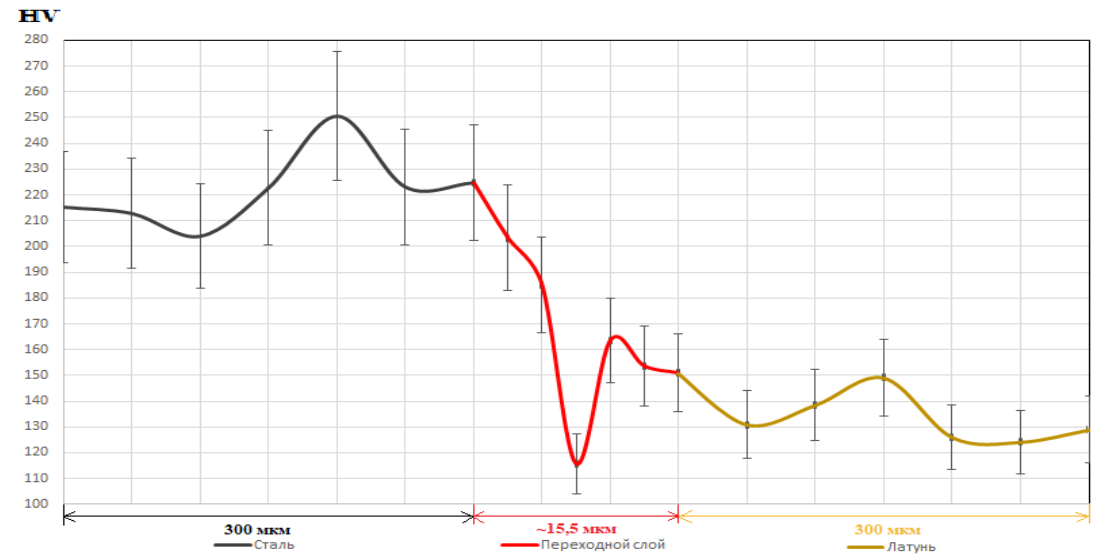

Рис. 13. График распределения показателя микротвердости

На снимке (рис. 2), полученным с помощью РЭМ, едва различим небольшой дефект на границе раздела между металлами. Этот фрагмент был рассмотрен более детально при большем увеличении: х100 (рис. 14), х250 (рис. 15), х500 (рис. 16) и х1000 (рис. 17), на которых видно, что дефект возможно представляет собой воздушные пузыри.

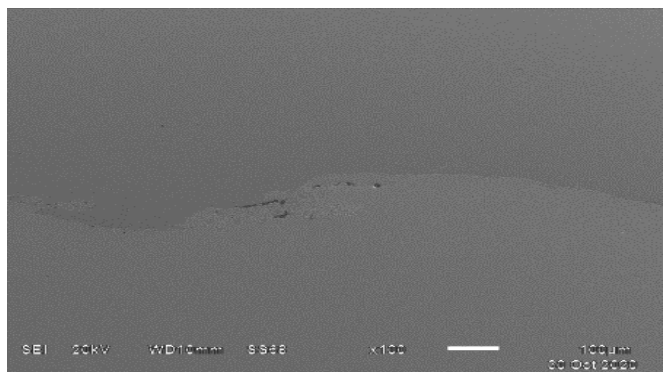

Рис. 14. Снимок границы раздела (увеличение х100)

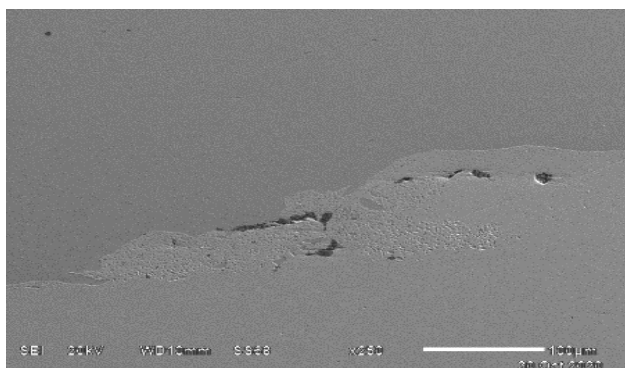

Рис. 15. Снимок дефекта при увеличении $\mathbf{x} 250$ 


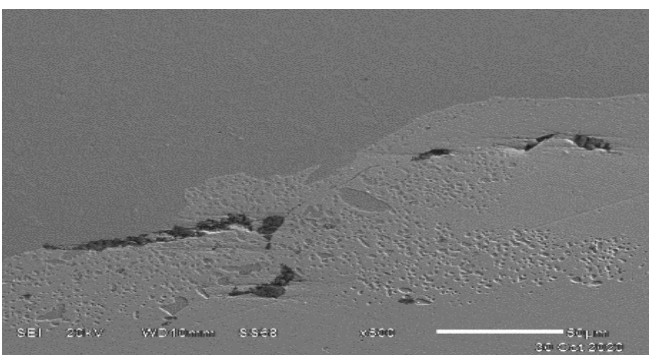

Рис. 16. Снимок дефекта при увеличении $\times 500$

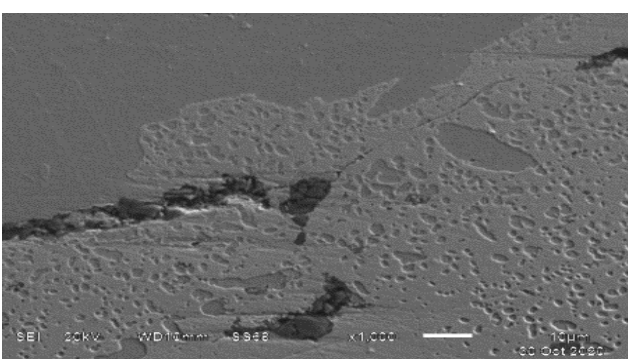

Рис. 17. Снимок дефекта при увеличении $\mathrm{x} 1000$

По результатам рентгеноспектрального микроанализа (рис. 18) составлена таблица (табл. 4), по которой можно определить, что на границе раздела между 3 и 4 спектрами увеличивается содержание углерода в 2-3 раза, по сравнению с его содержанием в стали. Помимо этого, в пограничном слое латуни обнаружены частицы кремния и железа.

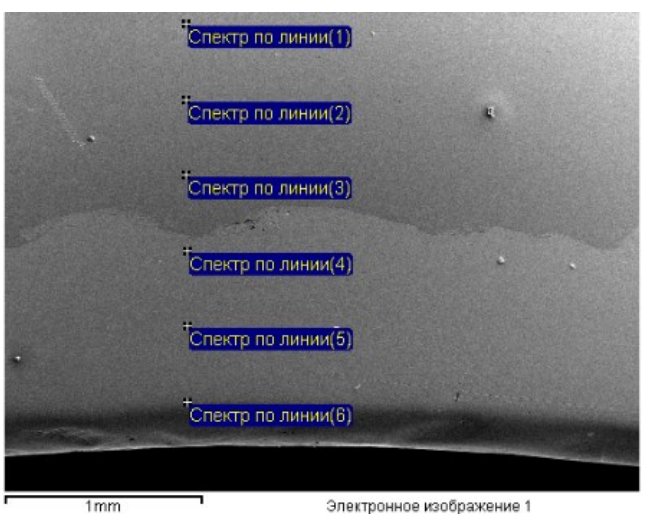

Рис. 18. Анализ по спектрам (увеличение х40)

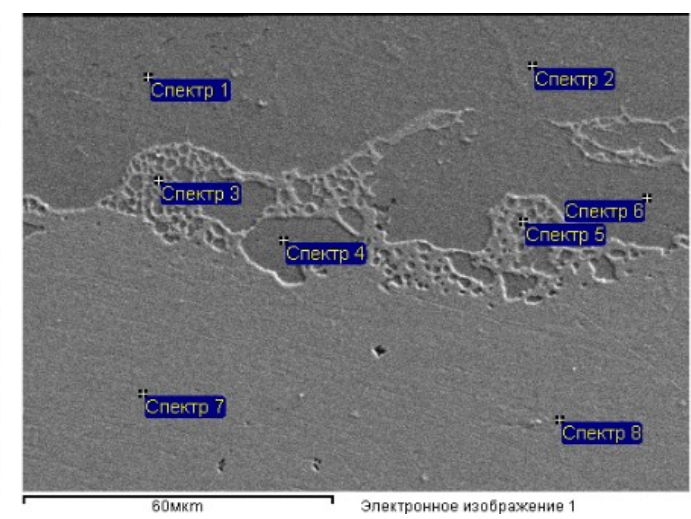

Рис. 19. Анализ участка без дефектов (увеличение х1000)

Таблица 4

Анализ всех элементов (нормализован) по рис. 18

\begin{tabular}{|c|c|c|c|c|c|c|c|c|c|}
\hline \multirow{2}{*}{$\begin{array}{c}\text { Спектр по } \\
\text { линии }\end{array}$} & \multicolumn{7}{|c|}{ Элементы в весовых \% } & \multirow{2}{*}{ Итог } \\
\cline { 2 - 10 } & $\mathrm{C}$ & $\mathrm{Si}$ & $\mathrm{Cr}$ & $\mathrm{Mn}$ & $\mathrm{Fe}$ & $\mathrm{Ni}$ & $\mathrm{Cu}$ & $\mathrm{Zn}$ & \\
\hline 1 & 2,82 & 1,09 & 0,85 & 0,75 & 93,91 & 0,58 & - & - & 100 \\
\hline 2 & 3,08 & 1,16 & 0,77 & 0,74 & 93,76 & 0,50 & - & - & 100 \\
\hline 3 & 5,65 & 1,40 & 0,93 & 0,74 & 90,74 & 0,55 & - & - & 100 \\
\hline 4 & 8,78 & 0,13 & - & - & 0,49 & - & 58,19 & 32,40 & 100 \\
\hline 5 & 9,88 & 0,22 & - & - & - & - & 59,05 & 30,84 & 100 \\
\hline 6 & - & - & - & - & - & - & 67,78 & 32,22 & 100 \\
\hline Макс. & 9,88 & 1,40 & 0,93 & 0,75 & 93,91 & 0,58 & 67,78 & 32,40 & \\
\hline Мин. & 2,82 & 0,13 & 0,77 & 0,74 & 0,49 & 0,50 & 58,19 & 30,84 & \\
\hline
\end{tabular}


Лупсанов А. Б., Милонов А. С., Мишигдоржийн У. Л., Номоев А. В. Исследование структуры, микротвердости и распределения химических элементов...

По результатам подробного анализа зоны без значимых дефектов при увеличении х1000 (рис. 19) составлена таблица (табл. 5), по которой можно определить, что пятна (спектр 3 и 5) образованы локальным расплавлением меди и цинка и образованием некоторых зон сплавов разных элементов входящих в состав стали и латуни. Исследование так же показывает, что взаимная диффузия железа, меди и цинка достаточна мала. Так, в переходном слое со стороны стали (в спектрах $1,2,4,6)$ содержание меди варьируется в весовых процентах от 0 до 1,72\%, цинка от 0 до $2,05 \%$, а со стороны латуни (в спектрах 7,8 ) содержание железа 0,68 и 0,88 весовых \% соответственно.

Таблица 5

Анализ всех элементов (нормализован) по рис. 19

\begin{tabular}{|c|c|c|c|c|c|c|c|c|c|}
\hline \multirow{2}{*}{ Спектр } & \multicolumn{7}{|c|}{ Элементы в весовых \% } & \multirow{2}{*}{ Итог } \\
\cline { 2 - 10 } & $\mathrm{C}$ & $\mathrm{Si}$ & $\mathrm{Cr}$ & $\mathrm{Mn}$ & $\mathrm{Fe}$ & $\mathrm{Ni}$ & $\mathrm{Cu}$ & $\mathrm{Zn}$ & \\
\hline 1 & 14,33 & 1,45 & 0,79 & 0,67 & 82,25 & 0,51 & - & - & 100 \\
\hline 2 & 5,74 & 1,01 & 0,73 & 0,54 & 90,63 & 0,74 & 0,61 & - & 100 \\
\hline 3 & 10,65 & 0,44 & 0,23 & 0,03 & 24,66 & - & 39,25 & 24,74 & 100 \\
\hline 4 & 8,77 & 1,21 & 0,71 & 0,00 & 85,34 & 0,21 & 1,72 & 2,05 & 100 \\
\hline 5 & 14,78 & - & - & - & 5,71 & - & 49,91 & 30,15 & 100 \\
\hline 6 & 10,11 & 1,52 & 0,75 & 0,07 & 84,56 & 0,34 & 0,96 & 1,69 & 100 \\
\hline 7 & 7,58 & - & - & - & 0,88 & - & 60,12 & 31,42 & 100 \\
\hline 8 & 9,78 & - & - & - & 0,68 & - & 57,58 & 31,96 & 100 \\
\hline Макс. & 14,78 & 1,52 & 0,79 & 0,67 & 90,63 & 0,74 & 60,12 & 31,96 & \\
\hline Мин. & 5,74 & 0,44 & 0,23 & 0,00 & 0,68 & 0,21 & 0,61 & 1,69 & \\
\hline
\end{tabular}

Детальное исследование состава химических элементов в дефекте, обнаруженным на рис. 15-17, представлено на следующих снимках (рис. 20 и рис. 21). По результатам анализов составлены таблицы (табл. 6 и табл. 7), по которым заметно, что в пузырях (пустотах) присутствуют различные оксиды металлов.

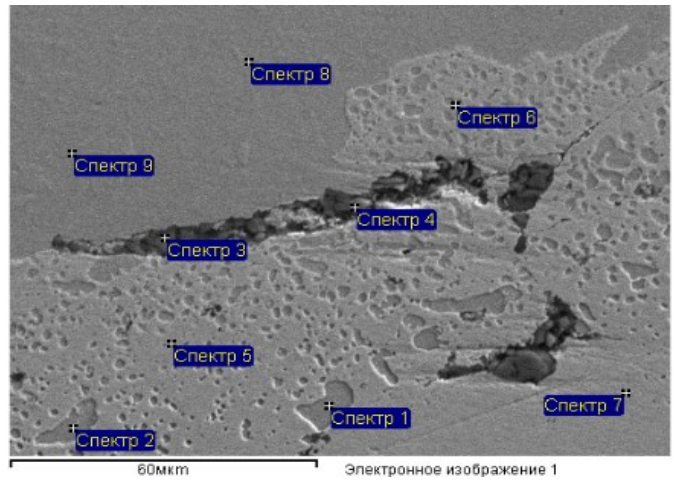

Рис. 20. Изображение дефекта при х1000 увеличении

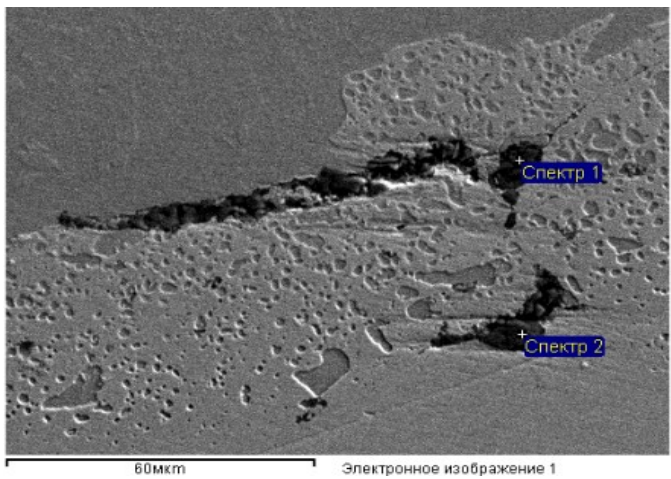

Рис. 21. Спектральный анализ воздушных пузырей при х1000 увеличении

В спектре 3 (рис. 20, табл. 6) обнаружено повышенное содержание кислорода, а также следы алюминия, кремния, калия, марганца и магния, что означает, 
что данный участок был загрязнен, предположительно частицами ВВ при сварке взрывом.

Таблица 6.

Анализ элементов (нормализован) по рис. 20

\begin{tabular}{|c|c|c|c|c|c|c|c|c|c|c|c|c|c|c|}
\hline \multirow{2}{*}{$\begin{array}{c}\text { Спек } \\
\text { p }\end{array}$} & \multicolumn{13}{|c|}{ Элементы в весовых \% } & \multirow[t]{2}{*}{ Итог } \\
\hline & C & 0 & $\mathrm{Mg}$ & Al & $\mathrm{Si}$ & $\mathrm{K}$ & $\mathrm{Ti}$ & $\mathrm{Cr}$ & $\mathrm{Mn}$ & $\mathrm{Fe}$ & $\mathrm{Ni}$ & $\mathrm{Cu}$ & $\mathrm{Zn}$ & \\
\hline 1 & 6,76 & - & - & - & 1,24 & - & - & 0,61 & - & 85,41 & - & 2,95 & 3,03 & 100 \\
\hline 2 & 13,75 & - & - & - & - & - & - & - & - & 5,23 & - & 50,99 & 30,03 & 100 \\
\hline 3 & - & 38,06 & 0,80 & 18,73 & 19,31 & 1,78 & 0,45 & - & 0,72 & 8,28 & - & 7,22 & 4,65 & 100 \\
\hline 4 & 18,52 & - & - & - & - & - & - & - & - & 6,24 & - & 48,36 & 26,88 & 100 \\
\hline 5 & 15,63 & - & - & - & - & - & - & - & - & 5,79 & - & 50,36 & 28,21 & 100 \\
\hline 6 & 19,02 & - & - & - & - & - & - & - & - & 2,62 & - & 51,10 & 27,26 & 100 \\
\hline 7 & 7,54 & - & - & - & - & - & - & - & - & 1,29 & - & 58,96 & 32,21 & 100 \\
\hline 8 & 5,66 & - & - & - & 1,11 & - & - & 0,75 & 0,52 & 89,94 & - & 1,23 & 0,78 & 100 \\
\hline 9 & 8,70 & - & - & - & 1,14 & - & - & 0,81 & 0,75 & 88,09 & 0,51 & - & - & 100 \\
\hline Иакс. & 19,02 & 38,06 & 0,80 & 18,73 & 19,31 & 1,78 & 0,45 & 0,81 & 0,75 & 89,94 & 0,51 & 58,96 & 32,21 & \\
\hline Иин. & 5,66 & 38,06 & 0,80 & 18,73 & 1,11 & 1,78 & 0,45 & 0,61 & 0,52 & 1,29 & 0,51 & 1,23 & 0,78 & \\
\hline
\end{tabular}

Анализ спектра 1 и 2 (рис. 21, табл. 7) показывает высокое содержание алюминия, который добавляется в виде порошка в различные смеси ВВ, используемых при сварке взрывом. На основании высокого содержания кислорода и углерода можно предположить, что там присутствуют частицы оксида алюминия и/или карбида алюминия, тогда воздушные пузыри могли образоваться из-за выделения газа $\left(\mathrm{CO}\right.$ и/или $\left.\mathrm{CO}_{2}\right)$ при протекании химических реакциях с ними.

Таблица 7

Анализ элементов (нормализован) по рис. 21

\begin{tabular}{|c|c|c|c|c|c|c|c|c|c|}
\hline \multirow{2}{*}{ Спектр } & \multicolumn{7}{|c|}{ Элементы в весовых \% } & \multirow{2}{*}{ Итог } \\
\cline { 2 - 10 } & $\mathrm{C}$ & $\mathrm{O}$ & $\mathrm{Al}$ & $\mathrm{Si}$ & $\mathrm{Mn}$ & $\mathrm{Fe}$ & $\mathrm{Cu}$ & $\mathrm{Zn}$ & \\
\hline 1 & 14,42 & 49,99 & 35,01 & - & - & 0,18 & 0,41 & - & 100 \\
\hline 2 & 30,59 & 33,14 & 21,19 & 0,68 & 0,64 & 0,31 & 8,96 & 4,50 & 100 \\
\hline
\end{tabular}

\section{Выводы и обсуждения}

В работе представлены результаты исследований микроструктуры, микротвердости и распределения химических элементов в пограничном слое сварных соединений, полученных посредством сварки взрывом, между пластинами стали Ст 3 и латуни Л 63 в биметаллическом подшипнике скольжения по типу «втулка».

На основании проведенных исследований, можно сделать следующие выводы:

1. Граница между металлами имеет волнообразную структуру, показатели длины и амплитуды волны которой существенно различаются по продольному направлению, средняя величина составляет $1,065 \times 10^{3}$ и 173 мкм соответственно.

2. Толщина пограничного (переходного) слоя варьируется в пределах от 1,3 до 43,7 мкм, среднее значение составляет 15,5 мкм. 
Лупсанов А. Б., Милонов А. С., Мишигдоржийн У. Л., Номоев А. В. Исследование структуры, микротвердости и распределения химических элементов...

3. В данном переходном слое наблюдается взаимопроникновение стали и латуни, чем достигается особо прочное соединение, обладающее комбинированными характеристиками микротвердости.

4. В процессе сварки взрывом могут наблюдаться локальные дефекты воздушные пузыри, предположительно вызванные загрязнением пластин следами взрывчатого вещества, используемого при данной сварке.

\section{Литература}

1. Родичев А. Ю. Технологическое повышение прочности сцепления и износостойкости антифрикционного покрытия биметаллических подшипников скольжения: дисс. ... канд. техн. наук. Орел: УНПК, 2011. 224 с.

2. Гаркунов Д. Н. Триботехника (износ и безызносность): учебник - 4-е изд., перераб. и доп. Москва: Изд-во МСXА, 2001. 616 с.

3. Дворецкий И. Х. Латинско-русский словарь. 2-е изд., перераб. и доп. Москва: 1976. $1096 \mathrm{c}$

4. Гаркунов Д. Н., Мельников Э. Л., Щедрин А. В., Бабель А. Л. Трибология на основе самоорганизации. Германия: LAP LAMBERT AcademicPublishing, 2015. 245 c.

5. Дерибас А. А. Физика упрочнения и сварки взрывом. Новосибирск: Наука, 1980. $220 \mathrm{c}$.

6. Райнхарт Дж. С., Пирсон Дж. Взрывная обработка металлов. Москва: Наука, 1966. $392 \mathrm{c}$.

7. Взрывная сварка // Большая советская энциклопедия: [в 30 т.] / гл. ред. А. М. Прохоров. 3-е изд. Москва: Советская энциклопедия, 1969-1978.

8. Батаев И. А. Формирование локализованных зон перемешивания в условиях высокоскоростного соударения металлических материалов и их влияние на структуру и свойства сварных соединений: диссертация на соискание ученой степени доктора технических наук. Томск: ИФПМ СО РАН, 2019. 348 с.

9. Матвеевский Р. М., Беркович Е. С., Рыньков Р. Н. Измерение микротвердости вдавливанием алмазных наконечников. (с Изменениями № 1, 2) ГОСТ 9450-76. (СТ СЭВ 1195-78). Москва: Издательство стандартов, 1993. 331 с.

10. Гринберг Б. А., Иванов М. А., Рыбин В. В. и др. Неоднородности поверхности раздела при сварке взрывом // Физика металлов и металловедение. 2012. Т. 113, № 2. C. $187-200$.

11. Андреевских Л. А., Дроздов А. А., Михайлов А. Л. и др. Исследование возможности создания сваркой взрывом биметаллических композиционных материалов высокожаростойкая порошковая сталь — медь // Сталь. 2015. № 1. С. 84-87.

12. Алымов М. И., Дерибас А. А., Гордополова И. С. О механизмах формирования контакта при сварке взрывом // Перспективные материалы. 2013. № 12. С. 51-55.

Статья поступила в редакцию 24.11.2020; одобрена после рецензирования 28.01.2021; принята к публикации 29.01.2021. 


\section{INVESTIGATION OF THE STRUCTURE, MICROHARDNESS AND DISTRIBUTION OF CHEMICAL ELEMENTS IN THE BOUNDARY LAYER OF A BIMETALLIC JOINT MADE OF STEEL AND BRASS, OBTAINED BY EXPLOSION WELDING}

Lupsanov $A$. B.

post-graduate student, Institute of Physical Materials Science of the SB RAS 670047, Russia, Ulan-Ude, Sakhyanovoy st., 6 lecturer, Buryat State University 670000, Russia, Ulan-Ude, Smolina st., 24a lupandrey@yandex.ru

Milonov A. S.

Ph.D. of Engineering Sciences, Senior Researcher, Institute of Physical Materials Science of the SB RAS 670047, Russia, Ulan-Ude, Sakhyanovoy st., 6 terwer81@mail.ru

Mishigdorzhiyn U. Lh. $\mathrm{Ph} . \mathrm{D}$. of Engineering Sciences, Head of the laboratory, Institute of Physical Materials Science of the SB RAS 670047, Russia, Ulan-Ude, Sakhyanovoy st., 6 druh@mail.ru, undrakh@ipms.bscnet.ru

Nomoev $A$. $V$.

Doctor of Physical and Mathematical Sciences, Associate Professor Head of the laboratory Institute of Physical Materials Science of the SB RAS 670047, Russia, Ulan-Ude, Sakhyanovoy st., 6 Associate Professor of the Department of General and Theoretical Physics Buryat State University 670000, Russia, Ulan-Ude, Smolina st., 24a nomoevav@mail.ru

Abstract. The paper presents the results of investigation of the microstructure, microhardness and distribution of chemical elements in the boundary layer of welded joints obtained by explosion welding between the plates of steel St 3 and brass L 63 in a bimetallic plain bearing of the "sleeve" type. Analysis of the boundary (transition) layer of the compound revealed a single defect - an "air bubble", presumably formed by gas products released during the chemical reaction of elements, an explosive. No other significant defects were found in the transition layer of the joint. The junction border has a wavy structure, where the average wave length and amplitude are $1,065 \times 10^{3}$ and $173 \mu \mathrm{m}$, respectively. The thickness of the boundary (transitional) layer varies from 1.3 to $43.7 \mu \mathrm{m}$, while the average value is $15.5 \mu \mathrm{m}$. In this transition layer, there is an interpenetration of steel and brass, which provides a particularly strong connection with combined values of microhardness. Keywords: explosion welding, bimetal, sleeve, boundary (transitional) layer, microstructure, microhardness. 
Лупсанов А. Б., Милонов А. С., Мишигдоржийн У. Л., Номоев А. В. Исследование структуры, микротвердости и распределения химических элементов...

For citation

Lupsanov A. B., Milonov A. S., Mishigdorzhiyn U. Lh., Nomoev A. V. Investigation of the Structure, Microhardness and Distribution of Chemical Elements in the Boundary Layer of a Bimetallic Joint Made of Steel and Brass, Obtained By Explosion Welding // Bulletin of Buryat State University. Chemistry. Physics. 2021; 1: 52-65 (In Russ.).

The article was submitted 24.11.2020; approved after reviewing 28.01.2021; accepted for publication 29.01.2021. 